\title{
Quantificazione mediante PCR dell'EBV-DNA da biopsie cutanee di pazienti con linfomi cutanei primitivi (micosi fungoide e sindrome di Sèzary)
}

Chiara Merlino, Massimiliano Bergallo, Cristina Costa, Mauro Novelli', Renata Ponti', Samuela Margio, Francesca Sidoti, Maria Elena Terlizzi, M. Ortoncelli', Rossana Cavallo, Maria Grazia Bernengo'

Dip. Sanità Pubbl. e Microbiol., SCDU Virologia,

'Dip. Scienze Biom. Oncol. Umana, Sez. Dermatol., Lab. Immunopatol. Cutanea;

Università di Torino

Key words: QC-PCR, EBV-DNA, CTCL

Quantification of EBV-DNA by PCR in skin biopsies from patients with primary cutaneous lymphomas (micosis fungoides and Sezary syndrome)

\section{SUMMARY}

Mycosis fungoides (MF), the most indolent form of CTCL, originates from a clonal expansion of epidermotropic helper/memory T cells. Sezary syndrome (SS) is a rare primay epidermotropic cutaneous T-cell lymphoma in leukemic. The aetiopathogenesis of MF and SS remains obscure despite several investigations. Infectious, environmental and genetic factors have been implicated as potential aetiological agents.

The studies investigating the role of EBV in CTCL present conflicting results. The different sensitivities of the technical methods used in the evaluation of the presence of viral DNA or virus-related antigens make comparison of the results difficult.

The aim of this study was to retrospectively evaluate the EBV-DNA load in skin biopsies from MF and SS patients by a highly sensitive (I-I0 EBV-DNA copies/reaction) quantitative-competitive PCR (QC-PCR) developed in our lab to better asses the relationship between EBV and CTCL.

Skin biopsies were obtained from 2I MF and IO SS patients; skin biopsies from a 8 patients with inflammatory skin disease were used as controls. EBV-DNA was detected in $70 \%$ of biopsies from SS patients vs. $0 \%$ of MF patients. No control patients resulted EBV-DNA positive, as expected. In addition, in SS patients, the survival from diagnosis is lesser in EBV-positive patients vs. EBV-negative patients even if not statistically significant. We are going to investigate the presence of EBV-DNA in peripheral blood of a larger number of patients and to evaluate the pattern of viral genes expression, to better assess the aetiopathogenetical role of EB virus in this kind of neoplasies.

\section{INTRODUZIONE}

La micosi fungoide $(\mathrm{MF})$ (1) è la forma più co mune dei linfomi cutanei a cellule T (CTCL) e può essere definita come un linfoma nonHodgkin periferico, epidermotropo a basso grado di malignità. Generalmente confinata alla cute, anche di tutto il corpo, mostra una graduale progressione clinica con una sequenziale comparsa di chiazze, placche e noduli tumorali.

La stadiazione è effettuata utilizzando la classificazione TNM. L'istologia evidenzia un infiltrato linfo-istiocitario dermico con variabile grado di epidermotropismo, cioè la presenza di elementi linfoidi atipici infiltranti l'epidermide o gli annessi, con singole cellule e/o piccoli clusters, filiere lungo la membrana basale o caratteristiche raccolte denominate "microascessi di Pautrier". I linfociti atipici presentano in genere nucleo convoluto o cerebriforme (cellule di Sézary). Dal punto di vista fenotipico sono cellule $\mathrm{T}$, generalmente helper CD4+ e raramente suppressor CD8+ (1).

La Sindrome di Sézary (SS) (1) è una rara variante leucemica dei linfomi cutanei primitivi a cellule $\mathrm{T}$, inclusa tra le forme aggressive.

Interessa esclusivamente gli adulti, in genere in età avanzata. La presentazione clinica è una triade caratterizzata da prurito, eritrodermia e linfoadenopatia. Spesso sono presenti distrofia ungueale, cheratosi palmo-plantare, facies leonina.

La prognosi è sfavorevole ed oltre alla progressione in linfoma ad alto grado, meno frequente, la morte spesso risulta dovuta alle complicanze infettive che insorgono per diminuzione delle difese legate alle barriere cutanee ed alla immunodepressione conseguente sia alla terapia che alla malattia stessa.

L'istologia è simile a quella della MF, con minor grado di epidermotropismo e in alcuni casi è dif- 
ficilmente differenziabile dalle dermatiti croniche. Le cellule di Sézary, presenti nella cute, ma soprattutto a livello ematico, sono linfociti atipici con nucleo ipercromico e convoluto (cerebriforme). Il fenotipo è generalmente $\mathrm{CD} 4+, \mathrm{CD} 26-$, CD7- (50\% dei casi) (2).

L'eziopatogenesi della MF e della SS è ancora ignota e sono stati suggeriti fattori genetici, ambientali ed infettivi (1). Recentemente, il retrovirus HTLVI ed herpesvirus umani sono stati coinvolti sia per la loro potenzialità di trasformazione oncogena diretta, sia perché capaci di infettare le cellule $\mathrm{T}$ e stabilire uno stato di latenza nei tessuti dell'ospite $(3,4)$.

Il virus di Epstein Barr (EBV), gamma-herpesvirus in grado di infettare in vivo i linfociti $\mathrm{B}$ e le cellule epiteliali dell'orofaringe, agente eziologico della mononucleosi infettiva, è notoriamente correlato al carcinoma nasofaringeo ed al linfoma endemico di Burkitt. Esso è stato anche associato ad altre forme tumorali sia epiteliali (carcinoma gastrico) che linfoproliferative (linfoma di Hodgkin, linfomi in situazioni di immunodepressione o immunodeficienza, linfomi T/NK extranodali (5).

Alcuni studi molecolari sul ruolo del virus di Epstein-Barr (EBV) nell'eziopatogenesi dei CTCL, hanno portato a risultati controversi, anche a causa della diversa sensibilità delle tecniche impiegate $(6,7,8)$.

In questo lavoro è stata indagata retrospettivamente la presenza e l'eventuale carica virale di EBV in biopsie cutanee di pazienti con MF e SS utilizzando una PCR quantitativa-competitiva (QC-PCR) con analisi densitometrica degli amplificati, altamente sensibile (1-10 copie di EBV-DNA/reazione) e riproducibile, messa a punto nel ns. laboratorio (9, modif).

\section{MATERIALI E METODI \\ Pazienti}

Sono stati studiati 21 pazienti con MF (17 MF, 11 maschi, 6 femmine, età mediana 63 anni, range 14-84 anni; $4 \mathrm{MF}$ in evoluzione verso linfoma ad alto grado di malignità, 2 maschi, 2 femmine, età mediana 74 anni, range 59-82 anni); 10 pazienti con SS (3 maschi, 7 femmine, età mediana 72 anni, range 46-84 anni) e 8 pazienti con patologie cutanee infiammatorie ( 6 maschi, 2 femmine, età mediana 64, 5 anni, range 33-79 anni) come gruppo di controllo.

\section{Estrazione del DNA}

Sono state tagliate sezioni di tessuto congelato (OCT criopreservante) di $20 \mathrm{~mm}$ e poste in provette da $1.5 \mathrm{ml}$. Le sezioni sono state lavate con PBS e sottoposte a digestione con proteinasi $\mathrm{K}$ per 3 ore a $56^{\circ} \mathrm{C}$. Il DNA è stato estratto utilizzando un kit per estrazioni da tessuto (QIAmp DNA Mini Kit, QIAGEN) secondo le istruzioni fornite dal fabbricante.

\section{Quantificazione dell'EBV-DNA mediante PCR quantitativa-competitiva (QC-PCR)}

E' stata utilizzata una double-step QC-PCR messa a punto nel nostro laboratorio (9, Bergallo et al., 2004 modificata).

In breve, il DNA estratto è stato sottoposto a screening mediante una PCR semiquantitativa basata sull'amplificazione in provette separate dei campioni clinici e di diluizioni scalari di uno standard esterno (4 diluizioni del plasmide bersaglio pEB171 contenenti 50, 100, 500 e 1000 copie, rispettivamente).

Sia i campioni clinici che lo standard esterno sono stati co-amplificati in presenza di 50 copie di plasmide pEB-C, utilizzato come controllo interno di amplificazione per valutare l'eventuale presenza di inibitori della Taq-polimerasi.

I primers utilizzati (WF1 e WR1) e le condizioni di amplificazione $\left(32\right.$ cicli; $1 \mathrm{~min}$ a $94^{\circ} \mathrm{C}, 1 \mathrm{~min}$ a $57^{\circ} \mathrm{C}, 1 \mathrm{~min}$ a $72^{\circ} \mathrm{C}$ ) sono quelli descritti precedentemente (Bergallo et al., 2004). I prodotti di amplificazione sono stati analizzati mediante migrazione elettroforetica in gel di agaroso al $2 \%$ e le bande sono state visualizzate mediante illuminazione UV dopo colorazione con bromuro di etidio.

Il numero di copie di EBV-DNA è stato determinato confrontando l'intensità delle bande del campione con quelle corrispondenti al numero di copie noto delle diluizioni di pEB171.

I campioni stimati contenere un numero di copie di EBV-DNA $>=$ a 1000 sono quindi stati quantificati mediante una QC-PCR con lettura densitometrica delle bande di amplificazione. E' stata generata una curva standard co-amplificando $1000,5000,10000$ e 50000 del plasmide bersaglio pEB171 e 5000 copie del plasmide competitore $\mathrm{pEB}-\mathrm{C}$.

I prodotti di amplificazione sono stati analizzati mediante gel-elettroforesi, e le bande sono state quantificate utilizzando un software per l'acquisizione digitale di immagini (Quantity One 1-D Analysis Software; BIO-RAD, USA).

I campioni sono stati quantificati co-amplificando il DNA estratto in presenza di 5000 copie del plasmide competitore pEB-C (controllo interno) e confrontando le bande digitalizzate degli amplificati con la curva standard.

I primers (WF1 e WR1) e le condizioni di amplificazione $\left(30\right.$ cicli; $1 \mathrm{~min}$ a $94^{\circ} \mathrm{C}, 1 \mathrm{~min}$ a $57^{\circ} \mathrm{C}, 1$ min a $72^{\circ} \mathrm{C}$ ) sono quelli descritti precedentemente (9 Bergallo et al., 2004). 
QC-PCR altamente sensibile da noi messa a punto, è risultata del 70\% nella SS e dello $0 \%$ nella MF. Come atteso, nei pazienti di controllo non è stata riscontrata la presenza di EBV-DNA. I pazienti con SS EBV-DNA positivi denotano un Hazard Ratio più che doppio (2.55) rispetto a quelli EBV-DNA negativi. Questo risultato, anche se le curve di sopravvivenza non sono statisticamente significative per la bassa numerosità dei campioni, è in accordo con quanto riportato da Foulc et al., 2003 (10) che hanno dimostrato per la prima volta il valore prognostico negativo del riscontro del genoma di EBV nella cute, probabilmente correlato con un marcato deficit immunitario nel corso di forme severe di SS.

Abbiamo intenzione di estendere lo studio ad un numero maggiore di pazienti, di valutare la presenza di EBV-DNA nel sangue periferico ed inoltre di studiare, utilizzando un approccio molecolare (nested RT-PCR), l'espressione dei geni litici e di latenza di EBV, allo scopo di approfondire le conoscenze sulla relazione tra questo virus ed $\mathrm{i}$ CTCL.

\section{BIBLIOGRAFIA}

1. Willemze R, Kerl H, Sterry W, et al. EORTC classification for primary cutaneous lymphomas: a proposal from the Cutaneous Lymphoma Study Group of the European Organization for Research and Treatment of Cancer. Blood 1997; 90: 354-71.

2. Bernengo MG, Novelli M, Quaglino P, et al. The relevance of the CD4+ CD26- subset in the identification of circulating Sezary cells. Br J Dermatol 2001; 144: 125-35.

3. Pancake BA, Zucker-Franklin D, Coutavas EE. The cutaneous $\mathrm{T}$ cell lymphoma, mycosis fungoides, is a human $\mathrm{T}$ cell lymphotropic virus-associated disease. A study of 50 patients. J Clin Invest. $1995 \mathrm{Feb}$; 95(2): 547-54.

4. Erkek E, Senturk N, Dincer I, et al. Identification of herpes simplex virus DNA and lack of human herpesvirus- 8 DNA in mycosis fungoides. Acta Derm Venereol. 2002; 82(3): 214-6.

5. Jaffe ES. Nasal and nasal-type T/NK cell lymphoma: a unique form of lymphoma associated with the Epstein-Barr virus. Histopathology. 1995 Dec; 27(6): 581-3.

6. Dreno B, Celerier P, Fleischmann M, Bureau B, Litoux P. Presence of Epstein-Barr virus in cutaneous lesions of mycosis fungoides and Sezary syndrome. Acta Derm Venereol 1994; 74: 355-57.

7. Jumbou O, Mollat C, N'Guyen JM, Billaudel S, Litoux P, Dreno B. Increased anti-Epstein-Barr virus antibodies in epidermotropic cutaneous T-cell lymphoma: a study of 64 patients. Br J Dermatol. 1997 Feb; 136(2): 212-6.

8. Foulc P, N'Guyen JM, Dreno B. Prognostic factors in Sezary syndrome: a study of 28 patients. $\mathrm{Br} \mathrm{J}$ Dermatol. 2003; 149: 1152-8.

9. Bergallo M, Merlino C, Daniele R, et al. Double-step PCR assay to quantify Epstein Barr viral load in peripheral blood. Mol Biotechnol 2004; 27: 187-96.
10. Kim EJ, Hess S, Richardson SK, et al. Immunopathogenesis and therapy of cutaneous $\mathrm{T}$ cell lymphoma. J Clin Invest. 2005 Apr; 115(4): 798-812.

\section{Chiara Merlino}

Dipartimento di Sanità Pubblica e di Microbiologia

SCDU Virologia

Via Santena 9; 10126 Torino

Tel.: 0116705639 - Fax: 0112365639

E-mail: chiara.merlino@unito.it 